\title{
Proteinates of Microelements are a Way to Increasing Milk Quality
}

\author{
Georgy Aleksandrovich Yarmots \\ Department of Feeding and Breeding of Farm Animals \\ Federal State Budgetary Educational \\ Institution of Higher Education \\ «Northern Trans-Ural State Agricultural University» \\ Tyumen, Russia \\ yarmozga@gausz.ru
}

\author{
Lyudmila Petrovna Yarmots \\ Department of Feeding and Breeding of Farm Animals \\ Federal State Budgetary Educational \\ Institution of Higher Education \\ «Northern Trans-Ural State Agricultural University» \\ Tyumen, Russia \\ yarmotslp@gausz.ru
}

\begin{abstract}
This paper reports on experience of using a feed additive based on proteinates of zinc, copper, manganese and selenium in various dosage. The studies have shown a positive influence on metabolic processes of cows during the increasing of milk production. Application of the feed additive facilitated increased digestibility of the main feed nutrients, as well as reduction of non-productive losses of gross energy with manure. Using the microelements allowed normalizing clinical blood scores, stimulating redox in the organism and promoting overall improvement of metabolism, increasing milk productivity and quality indicators of milk. Increased quantities of dry matter, fat and protein in milk have been registered. Introduction of the feed additive resulted in increased copper, zinc and selenium content in milk, which then may serve as a source of these elements in human nutrition.
\end{abstract}

Keywords - proteinates, microelements, nitrogen metabolism, morphological blood indicators, milk quality, feed additive.

\section{INTRODUCTION}

Actualization of genetic potential of dairy cattle productivity with simultaneously achieving high return of feed costs with production is possible only on condition of feeding regime that meets the demands of animals in all essential nutrients. Optimal quality and proportion of feeds with a correct balancing feed additive serve as a foundation of high productivity, good health and normal reproduction of health. Studies of processes that transform nutrients into produce when using feed additives allow increasing efficiency of feeding [1].

Currently, it is a common knowledge that a balanced mineral-rich diet plays an important role in supporting health of productive animals. One of the research tasks in this area is searching for ways to increase biological availability of microelements.

All the initial source components of the diet contain microelements in their proteins, carbohydrates, etc. During their evolution, animals had adapted to such forms of minerals, but modern technologies and high productivity lead to microelement deficiency. As a result, the deficient substances are added to the ration in inorganic or organic form.
Digestibility of microelements depend on many factors, including the forms in which they are present in feed mixes. Multiple studies have established that organic sources of microelements have a much higher biological availability compared to inorganic salts.

Traditionally, sulfates, carbonates or oxides of microelements are added to animal diet to satisfy the requirements of animal organisms. These salts disintegrate in the digestive tract forming free ions and then are absorbed.

Free ions of the microelements are highly active and may form complexes with other substances in the ration that are not absorbed that well. Digestibility of minerals in the digestive tract may vary significantly and under some conditions they may become completely unavailable after an undesired complete complexation. The higher the biological availability of a microelement, the higher is its activity and thus interaction with other components of the feed.

Application of inorganics in high dosage increases their competition with each other, leading to reduced availability of microelements. For example, because of absorption of zinc and copper ions, a deficiency in one of the elements may arise, even when its content in the feed is normal. Thus, currently, there is a growing interest to studying the role of organic sources of minerals (proteinates) in provision of high demands characteristic of modern genotypes.

Thanks to the organic forms, microelements are easily absorbed and digested even under stress conditions, without coming into antagonistic interactions with other microelements and nutrients. It gives them unique advantages in comparison with inorganic sources of minerals in feeding and metabolism.

Proteinates are absorbed in small intestine following the aminoacid absorption type and not that of metal ions (diffusion). They do not compete with other minerals for absorption sites; they are more stable and protected against various binding reactions with other minerals and nutrients. Proteinates have improved retention in tissues, making them capable of creating reserves sufficient for protection against diseases and supporting high reproductivity in highly productive animals. Proteinates reach organs and tissues easier and there is no need for overdosing, as they are better utilized 
by animals, thus promoting reduced pollution of the environment [2].

If regular microelements are absorbed at a rate of $30-40 \%$, for microelements in a protein form the absorption rate is $95 \%$ with only $5 \%$ removed from the body [3].

It is known, that proteinates of microelements are the most optimal form of biogenic metal compounds for the organism. In combination with organic compounds, activity of the microelements increases hundredfold in comparison with their ion state. Proteinates of microelements influence practically all kinds of metabolism.

One of the main causes of low productivity and high feed costs of production is a disbalanced mineral nutrition. Lack or deficiency of certain mineral elements, their incorrect proportion in the diet lead to reduced efficiency of feed utilization, reduce organism resisting powers significantly, cause deep disorders in general metabolism, deterioration of reproductive function, health and productivity $[4,5]$.

There is a certain relation between a mineral nutrition and a protein nutrition. Mineral balance of a diet increases a degree to which its nitrogen compounds are absorbed [6]. During the digestion process, the minerals provide optimal conditions for activity of digestive ferments in various sections of the animal digestive tract. They are also necessary for growth and development of microorganisms in the digestive tract $[7,8]$. The minerals create a $\mathrm{pH}$ level necessary for activity of hormones and ferments [9].

Insufficient or excessive availability of minerals to animals result in consequences that make their importance evident. The consequences may vary widely. Among them are decline in productivity and produce quality, reproductive disorders and appearance of nutritional diseases [10].

Each element has its own value and plays a separate role in the essential body functions.

Adsorption and digestion of a certain mineral, its participation in tissue growth and metabolic processes depend not only on quantity, but on the proportion of the elements, compared with both other elements and other components of the diet [11]. Experiments on cows have shown that under condition of a diet that is well-balanced with respect to mineral nutrition, absorption of nitrogen and protein synthesis increase.

In practice, taking cues from dietary recommendations for dairy cows from Russian as well as foreign authors is a laborious task due to a variation in climate zones throughout the country. Analysis of available data shows that these recommendations shall be rigorously detailed with respect for local peculiarities in feeding, physiological state of cows, concentrations of gross, digestible, metabolic and productive energies in the diet, content of certain nutrients, productivity and some other features [12].

A low productivity of dairy cows in some regions is largely due to a deficiency of cobalt, copper, calcium and sulfur in their winter diet and deficiency of phosphorus, calcium and magnesium in the summer one. Among the microelements, copper, cobalt, zinc, iodine, manganese and selenium play especially important roles.

Copper deficiency in a cow diet leads to serious metabolic disorders appearing as anemia and nervous system impairment; it also leads to reduced activity of cytochromoxidase, which in its turn causes disturbances in haem synthesis and iron absorption.

Satisfying the animal demand for copper depends on the amount of zinc and, especially, molybdenum coming with the feed. Manganese is essential for growth, activities of the central nervous system and reproductive function [13].

Zinc metabolism is linked to the amount of calcium in the diet. Zinc is the only microelement that is necessary for functioning of ferments of all six classes. Roles of zinc in cell biology are manifold. It provides protection of the body against various bacteria, fungi, parasites and viruses [14].

Importance of selenium for health is linked to its deficiency causing a white-muscle disease, at that, the risk of the disease is higher for faster-growing animals [15]. Selenium has a significant influence over metabolism in animal and human body, serving as a catalyst in redox processes, reacting to excess of heavy metal ions and facilitating their removal from the body [16]. Selenium plays an important role in protecting animals from mercury and cadmium poisoning. To enforce the activity of this element, the animals shall be provided with Vitamin E.

Selenium deficiency causes hypothyroidism symptoms, as it is found in iodinethyroninedeiodinase, which ensures transformation of thyroxine to tri-iodinethyronine, leading to reduction in the level of metabolic processes in the body and making it impossible to fully realize the genetic potential of the animal productivity [17].

Needs of cattle in selenium depend on activity of glutathione-peroxidase, which is defined by the nature and level of animal productivity. Selenium deficiency in feeds causes disorders in metabolism of proteins, fats and carbohydrates. Growing, pregnant and high yield-animals are especially prone to suffer from selenium deficiency [18]. Selenium additionally introduced into diet of ruminants ensures more active course of enzymatic processes and creates beneficial conditions for activity of infusorias, their growth and propagation [19].

Russian and foreign practical experience shows that a higher effect from adding biologically active substances to animal diet is attained when applying them in a form of special premixes. Scientifically developed premix recipes ensure optimal transport of nutrients to animals in correct proportion.

\section{MAIN OBJECTIVE}

The main research objective is a comparative study of various dosage of a complex organic feed additive onto cow metabolism and milk quality.

The basis of the feed additive is dry brewers' yeast, yeast extract, culture of Saccharomyces cerevisiae yeast and dry 
distillery dregs. Active components of the product are chelated microelements in a proteinate form: zinc, copper, manganese and selenium in the form of selenium-containing yeast.

\section{MATERIALS AND METHODS.}

Experimental part of the work was performed at the premises of the Instructional Farm of the Northern Trans-Ural State Agricultural University during the winter stall-feeding period on cows of Black Spotted breed during the first 100 days of lactation.

For the experiment, several groups of 10 animals each were formed with considerations for age, live weight, productivity and physiological state. Need in feeds and nutrients were calculated from recommendations of the Russian Academy of Agricultural Sciences.

During the experiment, the cows got the diet common in the farm, consisting of $38 \mathrm{~kg}$ of feed mix and $6 \mathrm{~kg}$ of grain mix. The cows in the 1 st experimental group additionally got $50 \mathrm{~g}$ of balancing feed additive, while those in the 2 nd experimental group got $75 \mathrm{~g}$ of the additive.

The experiment was accompanied with a physiological research aimed at animal metabolism and chemical composition of milk.

\section{RESEARCH RESULTS}

Increased efficiency of animal feeding consists of improving the quality of feeds and creating conditions for increased digestibility factor. Increase of digestibility by only one percent in the scale of the country would allow getting hundreds of kilograms of additional animal produce.

Cows in the 1st and 2nd experimental groups showed better digestion of organics by 1.29 and $1.85 \%(\mathrm{P}<0.05)$, better digestion of crude protein by $4.34(\mathrm{P}<0.01)$ and $5.86 \%$ $(\mathrm{P}<0.01)$, better digestion of crude fiber by 0.84 and $2.81 \%$ $(\mathrm{P}<0.05)$ in comparison with the animals in the control group.

From analysis of digestibility factors obtained in the physiological experiment, one may note, that the efficiency of nutrient adsorption was higher in the cows of the 2 nd group in comparison to both control and the 1 st experimental group.

Provision of animals with available energy is one of the main factors that define the level of their productivity. The problem of energy supply takes the central place in the theory of feeding of farm animals.

Intensive metabolism of high yield cows influences the level of energy balance. Thus, increasing the biological adequacy of a diet by introducing vital microelements allows adapting the body of a cow to an intense physiological state and reducing the adverse effect of the negative energy balance typical during the first third of lactation.

Consumption of gross energy with the feed was higher in the 1 st and 2 nd experimental group as compared to the control group, by 2.32 and $4.62 \%(\mathrm{P}<0.05)$ respectively.

Metabolic energy was maximally used by the cows in the 2nd experimental group. The animals from the 2nd experimental group spent $6.62 \%(\mathrm{P}<0,01)$ and $2.40 \%$ more metabolic energy than the cows from the control and the $1 \mathrm{st}$ experimental group respectively. Formation of produce, i.e., milk, is also directly linked to expenditure of physiologically useful energy. The cows in the 2nd experimental group allocated much more energy to milk synthesis, than the cows in the control and the 1 st experimental group, by $6.50 \%$ and $3.69 \%$, respectively.

All the vital processes in the body where minerals are involved are related to protein metabolism. Formation and breakdown of proteins in the animal body happens at the expense of nitrogen compounds in feed. Demand of ruminants for nitrogen compounds is a total of needs in pure protein for life support and that for productive purposes.

Balanced nature of diet, as well as biological adequacy of the protein supply may be assessed by nitrogen balance and use.

As it is known, during digestion, absorption and intermediary metabolism, the feed nutrients undergo significant changes. A nitrogen balance has been calculated from the data obtained in the physiological experiment, chemical composition of feeds, residues, manure, urine and milk.

Animals in the 1st and 2nd experimental group showed reliably more consumption of nitrogen from feed than the animals in the control group. The difference in nitrogen consumption for the 1 st experimental group amounted to 24.7 $\mathrm{g}$ or $7.08 \%$, for the 2 nd experimental it amounted to $28.17 \mathrm{~g}$ or $8.08 \%$. However, gross supply of nitrogen cannot serve as an efficiency indicator for dietary nitrogen utilization. For lactating cows, it is more important to trace the distribution of nitrogen between the excretory wastes, milk and accumulation in the body.

The cows from the 1 st and 2nd experimental groups excreted more nitrogen with milk than the cows of the control group. However, the reliable difference was observed only for the cows in the 2 nd experimental group, it amounted to 20.14 g or $15.55 \%(\mathrm{P}<0.01)$.

The animals in all the groups had positive nitrogen balance. However, in the 1 st and 2 nd groups it was significantly higher. The nitrogen balance in cows of the $1 \mathrm{st}$ experimental group amounted to $26.12 \mathrm{~g}$, which is $18.66 \mathrm{~g}$ larger than in animals of the control group; for the animals in the 2nd experimental groups these values are $18.62 \mathrm{~g}$ and $11.16 \mathrm{~g}$ respectively. The high coefficient of nitrogen use may be explained by the fact that the animals in the experiment were in their first lactation period and had not finished growing yet.

Maximum use of nitrogen for synthesis of produce has been observed in the cows of the 2 nd experimental group. The utilization coefficient of nitrogen for milk amounted to $39.72 \%$ in the cows of the 2 nd experimental group, which is $2.57 \%$ higher than in the cows of the control group and by $2.74 \%$ higher than in the animals of the 1 st experimental group. 
Studies of the mineral balance have shown that while supply of calcium with the feed was relatively uniform, the nature of its utilization by the cows in the experiment varied. The cows in the 2nd experimental group reliably showed more utilization of dietary calcium for milk synthesis. The difference was $2.41 \mathrm{~g}$ or $6.29 \%(\mathrm{P}<0.05)$ in favor of the cows from the 2nd group.

Animals in all the groups had positive calcium balance, however, in the 1 st and the 2 nd experimental groups, the accumulation of calcium was $4.00 \mathrm{~g}(19.49 \%)$ and $1.45 \mathrm{~g}$ $(7.07 \%)$ higher, respectively, than in the control group.

The amount of phosphorus consumed with the feed was reliably higher in the cows of the 2nd experimental group, by $3.13 \mathrm{~g}$ or $4.17 \%(\mathrm{P}<0.01)$ than in the animals in the control group. The cows of the 2nd experimental group utilized reliably more phosphorus $(\mathrm{P}<0,01)$. The difference as compared with the control group amounted to $3.43 \mathrm{~g}$ $(13.69 \%)$, as compared with the 1 st experimental in was 3.44 $\mathrm{g}(13.74)$.

Phosphorus balance was positive in animals of all the groups in the experiment. However, the cows from the 1st experimental group accumulated phosphorus in their organisms more intensively. Maximum utilization of phosphorus for synthesis of milk has been observed in the cows of the 2nd experimental group. There, the phosphorus utilization coefficient for produce amounted to $36.46 \%$ of the amount acquired with feed.

Among the important animal husbandry studies for determining interior features of an animal are analyses of morphological composition, physical and chemical characteristics of blood. Blood fulfills a multitude of functions providing the necessary conditions for functioning of the organism. Blood composition largely depends on the condition of the organism as a whole and that of its organs and tissues. Insufficient or excessive supply of nutrients breaks the course of metabolic processes in tissues, which is directly reflected in blood composition.

Thus, for objective assessment of organism condition, data from morphological analysis of blood is needed in addition to the data from biochemical research [20]. Taking into account the important role of blood, morphological and biochemical analysis of blood was undertaken during the research.

The blood of the cows from the 1st and 2nd experimental groups has shown $5.02 \%$ and $5.34 \%$ more erythrocytes respectively, as compared to the control group values; hemoglobin indicators were 0.80 and $2.73 \%$ higher respectively.

Content of hemoglobin in erythrocytes taken from the cows of the experimental groups was higher. The hemoglobin level in the blood of the cows from the 1st and 2nd experimental groups was 0.80 and $2.73 \%$ higher, while the color index was 0.98 and $14.7 \%$ higher as compared to the values shown by the control group.

The color index in the 2nd experimental group increased by $0.15 \%$ as compared to the 1 st group and by $14.7 \%$ as compared to the control group. Increased hemoglobin and color index point supremacy of animals from the 2nd experimental group in intensity of cellular respiration in comparison with those in the control and the 1st experimental groups.

Thus, application of the organic form of the microelements (zinc, copper, manganese and selenium) in the diet promotes normalization of clinical blood scores, stimulates redox processes in the body and in general, facilitates improved metabolism and increased productivity.

Leukocytes have bacterial activity, amplify mitotic activity and improve tissue regeneration [21]. Leukocyte count was higher in the blood of the cows from the 1 st and the 2nd experimental group, by 16.86 and $22.84 \%$ respectively.

Morphological blood indicators of the experimental animals were within the boundaries of physiological norm and did not show reliable deviations. Biochemical blood scores for all the groups were also within the boundaries of the physiological norm.

Alkali reserve of blood is an indicator of metabolic profile of animals which is used to assess their health condition. The alkali reserve was higher in the cows of the 1st and 2 nd experimental group 2.79 and $4.66 \%(\mathrm{P}<0.01)$, as compared to the same of the control group.

Filtrate nitrogen, that is, nitrogen from non-protein components of blood plasm, is very important in blood-related research. This indicator characterizes intensity of protein metabolism. Its disturbance leads to accumulation of metabolic waste products and intermediaries, and the value of filtrate nitrogen significantly increases going beyond the limits of a norm. There was $10.92 \%$ more of filtrate nitrogen found in the blood of the cows from the control group as compared to the animals in the 1 st experimental group and $46.85 \%$ as compared to the animals in the 2 nd experimental group. This is an evidence of a significant accumulation of protein decay product in the bodies of animals in the control group.

The blood of the cows from the 1st and 2nd experimental groups has shown $3.23 \%$ and $7.53 \%$ more total nitrogen respectively, as compared to the control group values. However, no significant difference was found between the groups for this indicator.

Studies of crude protein content and its fractions in blood serum have shown that in all the groups the crude protein content was within the limits of the physiological norm. Crude protein content in the 1st and 2nd experimental groups showed insignificant variation and was in the range of 69.83-70.28 g/l, which is higher than in the control group animal, by 6.74 and $7.43 \%$, respectively.

Studies of protein fractions have shown, that the highest albumen percentage was found in the blood serum of the cows from the 1st and 2 nd experimental blood at $37.40 \%$, which is $1.67 \%$ higher than in the control group.

Globulin-rich fraction of proteins includes $\alpha-, \beta$ - and $\gamma$ globulins Decrease of the globulin-rich fraction is observed in high-yield animals during the increase in milk yield. It is caused largely by a decreased amount of $\gamma$-globulins. 
While increasing the milk yield, high-yield cows have a higher $\alpha$-globulin blood content than during the subsequent stages of lactation. The $\alpha$-globulins are specialized as carrier proteins, which is explained by their high reaction ability allowing their binding with many compounds. The blood of the cows from the 1st and 2nd experimental groups has shown $0.38 \%$ and $1.04 \%$ higher $\alpha$-globulin content respectively, as compared to the control group values. The $\beta$-globulins have a pronounced capacity to form complexes with many blood compounds, but most of all this capacity manifests with respect to lipids, that is, the level of $\beta$-globulins directly related to the milk fat content [21].

The level of $\beta$-globulins in the blood serum of the animals from the 2nd experimental group was the highest and amounted to $9.93 \%$. The cows of this group had reliably higher fat content in milk than the animals in the 1st experimental and the control group. The $\gamma$-globulins fraction is the least mobile and the heaviest. The share of this fraction is usually reduced in more productive animals. In the control group, this fraction took up $40.21 \%$, which is 2.37 and $3.56 \%$ higher than in the 1st and 2nd experimental groups, respectively.

Solution of the task to increase milk quality necessitate taking into account a multitude of factors that promote increasing total dry matter content, including fat content and protein content.

Milk is a source of the most of minerals necessary for growth of a young organism. Microelements, while not having caloric value, participate in all the metabolic processes, including milk synthesis. A number of factors, the main one being the feed, defines minerals-to-milk transition intensity. It has been established, that increasing their content in a diet leads to increased concentration of these elements in milk.

In optimization of animal diets with respect to deficient elements a lot of attention is paid to organic compounds of microelements; research in this direction produced a multitude of papers in recent years [13].

The studies have shown that the cows that got the feed additive realized their genetic potential to a larger degree and utilized the dietary nutrients more efficiently for milk synthesis.

The highest milk yield with natural fat content during the first third of lactation was obtained from the cow of the 2 nd experimental group, amounting to $2969.33 \mathrm{~kg}$, which is $375.33 \mathrm{~kg}$ or $14.47 \%$ higher than that of the animals in the control group and $194.00 \mathrm{~kg}$ or $6.99 \%$ higher than that of the animals in the 1st experimental group.

The highest milk yield recalculated for $4 \%$ fat content was also obtained from the cows of the 2nd experimental group, amounting to $3192.03 \mathrm{~kg}$, which is $675.21 \mathrm{~kg}$ or $26.83 \%$ $(\mathrm{P}<0.001)$ higher than that of the animals in the control group and $382.01 \mathrm{~kg}$ or $13.59 \%(\mathrm{P}<0.001)$ higher than that of the animals in the 1 st experimental group.

The amount of milk fat obtained from the cows in the 2nd experimental group reliably exceeded that of the control group by $26.98 \mathrm{~kg}$ or $26.80 \%(\mathrm{P}<0.001)$.
Introduction of the feed additive into diet positively influenced not only milk fat content, but milk protein content in the cow milk as well. During the experiment, the cows from the 2nd experimental group provided reliably more milk protein that the cows in the control group, by $15.55 \%$ $(\mathrm{P}<0.01)$.

During the studies, chemical composition indicators and some physical and chemical properties of milk from the cows participating in the experiment were analyzed (Table 1).

TABLE I. CHEMICAL COMPOSITION OF COW MILD DURING THE EXPERIMENT, $(\mathrm{X} \pm \mathrm{SX}) \mathrm{N}=10$

\begin{tabular}{|l|c|c|c|}
\hline \multirow{2}{*}{ Indicator } & \multicolumn{3}{c|}{ Group } \\
\cline { 2 - 4 } & Control & $\begin{array}{c}\text { 1st } \\
\text { Experimental }\end{array}$ & $\begin{array}{c}\text { 2nd } \\
\text { Experimental }\end{array}$ \\
\hline Dry matter, \% & $12.24 \pm 0.11$ & $12.49 \pm 0.25^{*}$ & $12.80 \pm 0.4^{* *}$ \\
\hline Fat, \%wt & $3.88 \pm 0.05$ & $4.05 \pm 0.21$ & $4.30 \pm 0.10^{* *}$ \\
\hline Protein, \%wt & $3.12 \pm 0.19$ & $3.11 \pm 0.19$ & $3.15 \pm 0.02$ \\
\hline Lactose, \%wt & $4.47 \pm 0.06$ & $4.54 \pm 0.04$ & $4.56 \pm 0.02$ \\
\hline Energy value, kcal & 67.20 & 69.03 & 71.60 \\
\hline Minerals, \%wt & $0.773 \pm 0.01$ & $0.785 \pm 0.006$ & $0.788 \pm 0.0008$ \\
\hline Copper, $\mu \mathrm{g} / \mathrm{kg}$ & $122.0 \pm 3.0$ & $129.0 \pm 2.0$ & $123.0 \pm 1.2$ \\
\hline Zinc, $\mu \mathrm{g} / \mathrm{kg}$ & $3410.0 \pm 80.0$ & $3400.0 \pm 40.0$ & $3400.0 \pm 60.0$ \\
\hline Selenium, $\mu \mathrm{g} / \mathrm{kg}$ & $23.0 \pm 1.3$ & $26.0 \pm 3.1$ & $34.0 \pm 2.8^{*}$ \\
\hline Calcium, g/kg & $1.48 \pm 0.01$ & $1.29 \pm 0.02$ & $1.37 \pm 0.01$ \\
\hline Phosphorus, g/kg & $0.97 \pm 0.02$ & $0.90 \pm 0.01$ & $0.96 \pm 0.01$ \\
\hline
\end{tabular}

\section{CONCLUSION}

During the studies of qualitative content of milk, an increased dry matter content in the milk from the cows in experimental groups was noted.

Milch cows release a lot of minerals with milk. The higher the daily milk yield, the higher is the mineral concentration necessary in their diet to cover the demand for them in the animals.

Minerals are supplied to the animals with feed and feed additives to be transfered into milk. They have an important physiological and technological significance in milk processing. Milk contains all the elements than ensure mineral metabolism in the body, normal growth and development of an animal. Currently, the problem of quality of milk and dairy produce is a pressing global issue. In milk, the microelements are binded with proteins and fat globule membranes. Their content depends on diet, lactation stage, health condition of animals and in total amounts to $800 \mu \mathrm{g}$ per $100 \mathrm{~g}$ of milk, or about $0.1 \%$ of all the minerals [22].

After introduction of the feed additive, the copper and zinc content in milk from the cows in the experimental groups was within the normal limits. There were no reliable difference with the milk from the control group cows in copper and zinc content. The selenium content was higher in the cows of the 
1st and 2nd experimental group, by 13.04 and $47.83 \%$ $(\mathrm{P}<0.05)$, as compared to the same of the control group.

Introduction of the feed additive promoted increased selenium content in the diet of the 1 st and 2 nd experimental groups, up to $0.23 \mathrm{mg} / \mathrm{kg}$ and $0.31 \mathrm{mg} / \mathrm{kg}$ of dry weight, respectively. Selenium content in the diet of the cows in the control group amounted to $0.08 \mathrm{mg} / \mathrm{kg}$ of dry matter. Thus, increasing the selenium content in feeds promoted its higher transition into milk, which is important for producing preventative foodstuffs.

Thus, studies of milk productivity in the experimental animals have shown that the feed additive with organic forms of the essential microelements had a positive effect on both the level of milk productivity and qualitative content of the milk.

\section{References}

[1] I.O. Kirnos, I.V. Suslova, V.M. Duborezov, Adaptive feeding system is a governing factor in full implementation of genetic potential of cows, Zootechnia, 2011, no. 9, pp. 9-11.

[2] V. Nadeyev, M. Chabayev, R. Nekrasov, Yu. Klementieva, M Klementiev, Efficiency of organic copper application in diet of fattened pigs, Glavnyi Zootekhnik, 2012, no. 5, pp. 22-26.

[3] B. Ebbinge, Advanced technologies in feeding of ruminants, Zootekhnik, 2007, no. 5, pp.26-27.

[4] A.V. Arkhipov, L.V. Toropova, High quality feeds are a success formula for dairy cattle operations, Annals of Bryanks State Agricultural Academy, Bruansk, 2010, no. 3, pp. 3-23.

[5] L. Toropova, S. Serebrennikova, V. Galamov, V. Lutsyuk, I. Toropova, $\mathrm{V}$. Andreyev, Efficiency of orgago-mineral additives in animal feeding, Glavnyi Zootekhnik, 2012, no. 1, pp. 16-26.

[6] P.F. Shamakov, Increasing the adequate nature of nutrition and diet nutrient digestibility and absorption by farm animals and poultry, Feed supplies of Western Siberia and their rational use: A collection of scientific papers, Omsk State Agricultural Academy - Omsk: Oblast regional printing house, 2005, pp. 17-50.
[7] I.S. Shakatonov, Factors affecting providing animals with vitamins / I.S. Shalatonov, Zootechnia, 2004, no.6, pp. 15-16.

[8] I.O. Kirnos, V.M. Duborezov, Efficiency of mineral additives during increasing the milk yield, Proceedings of the III International Scientific and Practical Conference Modern Technological and Selection-related aspects of development of Russian animal farming, Moscow: Dubrovsty, 2005, pp. 50-51.

[9] S.A. Avakyants, Vitamin and mineral premixes produced by the Yerevan plant, Kombikorma, 2000, no. 1, pp. 28-29.

[10] V.L. Kryazheva, Cobalt metabolism in cows additionally fed with synthetic methionine, Zootechnia, 2004, no. 11, p.12.

[11] N.A. Lushnikov, O.N. Grekhova, Using Zyryan bentonites as a filler in a premix for piglets, Rational use of Trans-Ural feed supplies: A collection of papers dedicated to the 60th anniversary of Kurgan State Agricultural Academy named after Maltsev, Kurgan, 2003, pp.110-120.

[12] L. Morozova, Biologically active substances in diet of lactating cows, Dairy and Beef Cattle Farming, 2009, no. 1, p. 28-29.

[13] S. A. Kuznetsov, A. Kuznetsov, Role of Vitamins and Minerals in Regulation of Reproductive Function in Cows, Dairy and Beef Cattle Farming, 2010, no. 5, p. 32-34.

[14] A. Petrosian, Microelements and Immunity, Zhivotnovodstvo Rossii, 2011, no. 9, p. 58-59.

[15] N. Sadovnikova, Selenium: Forms and Functions, Zhivotnovodstvo Rossii, 2008, no. 8, pp. 59-60.

[16] V. Fisinin, P. Suray, Natural Minerals in Feeding Animals and Birds, Zhivotnovodstvo Rossii, 2008, no. 8, pp. 66-68.

[17] L. Toropova, D. Trukhin, Influence of Vitabelin on Productivity of Lactating Cows, Glavnyi Zootekhnik, 2009, no. 12, pp.17-20.

[18] I.V. Suslova, I.V. Ivanova, V.M. Duborezov, Optimal content of selenium in the diet of fattened male calves, Zootechnia, 2009, no. 11, pp. 6-8.

[19] I.N. Akhmetova, Influence of Organic Selenium on Nutrients Digestibility in Male Calves, Zootechnia, 2008, no. 7, pp.12-13.

[20] M.F. Yudin, Physiological Status of Organism in Different Seasons, Veterinaria, 2000, no. 2, pp. 38-41.

[21] S.D. Batanov, O.S. Starostina, Blood composition and its link to milk producing ability of cows, Zootechnia, 2005, no. 10, pp.14-17.

[22] K.K. Gorbatova, Biochemistry of milk and dairy products: A Study Guide, Saint Petersburg: Giord, 2003. 